\title{
FRANCİS TÜRBİNLERİNDE YÖNLENDİRME KANAT AÇISININ ÇARK MUKAVEMETİNE VE TÜRBİN VERİMİNE ETKİSí
}

\author{
Adnan SÖZEN*, Selçuk KEÇEL**, H.Güçlü YAVUZCAN** \\ *Gazi Üniversitesi, Teknoloji Fakültesi, Enerji Sistemleri Mühendisliği Bölümü, 06500, Teknikokullar Ankara \\ **Gazi Üniversitesi Mimarlık Fakültesi, Endüstri Ürünleri Tasarımı Bölümü, 06500, Maltepe Ankara \\ asozen@gazi.edu.tr, kecel@gazi.edu.tr, gyavuzcan@gazi.edu.tr
}

(Geliş/Received: 16.09.2013; Kabul/Accepted: 20.03.2014)

\begin{abstract}
ÖZET
Hidroelektrik santrallerde enerjinin etkin dönüşümünü sağlayan türbinler karmaşık yapıları ve tasarımları bakımından önem taşıyan bileşenlerden biridir. Bu çalışmada hidroelektrik santraller için düşü ve güç gibi temel parametreleri belirli olan bir Francis tipi türbin ve çıkış borusu için akış analizleri hesaplamalı akışkanlar dinamiği (HAD) hesapları yapılmıştır. Çalışmanın temel amacı türbinden maksimum gücü elde edebilmek için optimum yönlendirme kanat açısının tespitidir. Maksimum güce ulaşırken rotor kanatlarında oluşan eşdeğer gerilmelerin malzeme dayanımı üzerindeki etkileri de irdelenmiștir. Maksimum moment, hidrolik ve çark verimi ile türbin gücü $25^{\circ}$ yönlendirme kanat açısında elde edilmiş olup eşdeğer basınç 6,7 MPa olarak hesaplanmıştır.
\end{abstract}

Anahtar Kelimeler: Francis türbin, yönlendirme kanat açısı, verim, mukavemet

\section{THE EFFECT OF THE ANGLE OF THE WICKET GATE ON TURBINE EFFICIENCY AND STRENGTH IN FRANCIS TYPE TURBINES}

\begin{abstract}
Turbines which provide active transformation of the energy in hydroelectric power plants are one of the significant components regarding their design and complex structures. In this study, computational fluid dynamics (CFD) calculations for a Francis type turbine whose fundamental parameters like head and power are definite and outlet pipe flow analyses of hydroelectric plants were done. The main purpose of the study is to determine optimum guidance wicket gate angle for obtaining maximum power from turbine. As reaching to maximum power, the effects of equivalent stresses formed in rotor blades on mechanical strength were also examined. Maximum torque, hydraulic and rotor efficiency, and turbine power was obtained from a guidance blade angle of $25^{\circ}$, equivalent pressure was calculated as $6.7 \mathrm{MPa}$.
\end{abstract}

Keywords: Francis turbine, angle of wicket gates, efficiency, strength

\section{GÍRİŞ (INTRODUCTION)}

Hidroelektrik santrallerde çalışma parametrelerine uygun türbin tasarımlarının yapılabilmesi için akış hesaplarının yapılarak boyutlandırılması, zaman, maliyet ve doğruluk açısından son yillarda hesaplamalı akışkanlar dinamiği (HAD) programları ile daha kısa bir sürede gerçekleşmektedir.

Hesaplamalı Akışkanlar dinamiği analizleri, hidrolik güç ekipmanlarının akış karakteristiklerini göstermeye olanak sağlayan güçlü tasarım araçlarına sahiptir. Birçok araştırmacı, Francis tipi türbinlerin sayısal analizinde rotor stator etkileşimleri, kavitasyon davranışları, farklı yükleme altındaki performansları incelerken HAD uygulamalarından faydalanmışlardır [1-13]. Saaed ve arkadaşları tarafından hazırlanan çalışmada, türbin kanatlarındaki gerilmelerin azaltılmasına yönelik olarak kurulan farklı modeller incelenmiştir. $\mathrm{Bu}$ modeller üzerinde farklı yükleme ve debi değerlerinde radyal ve teğetsel hız bileşenleri ve çark kanatlarının dayanımları incelenmiştir [2]. Yıldız ve Çelebioğlu tarafından yapılan parametrik modellemede çıkış borusundaki 
akış ve boruların yapısal analizi yapılmıştır. Yapısal analizde toplam deformasyon ve gerilme kuvvetleri görselleştirilmiştir [3]. Okyay ve arkadaşları tarafından yapılan başka bir çalışmada Sayısal Akışkanlar dinamiği ile ilgili yapılan Francis tipi türbin tasarımı gerçekleştirilmiş ve sabit kanatlar etrafındaki ızgara yapısı ile salyangozdaki basınç değişimi genel olarak gösterilmiştir [4]. Chen ve Çelebioğlu tarafından yapılan çalışmada, sonlu elemanlar yöntemi ile bir Francis türbinin çark ve ayar kanadında akım tarafindan oluşturulan gerilmeler incelenmiştir. Burada, farklı çalışma basınçları için, hareketli parçalarda yüksek hızda dönüş yüzünden oluşan yüklemeler incelenmiştir. Basınç yüklemeleri değişik çalışma koşullarındaki hesaplamalı akışkanlar dinamiği çözümlemelerinden elde edilmiştir. Çark kanatları gibi türbin parçalarındaki karma kuvvetlerin etkilerini anlayabilmek için, bu parçalardaki gerilme dağılımları değişik çalışma koşullarında hesaplanmıştır [5]. Nilsson ve Davidson tarafindan hazırlanan çalışmada ise Kaplan ve Francis tipi su türbin çarkları için çıkış eksenlerinde açıların değiştirilerek belirli mesafelerdeki hız ve basınç etkinliklerinin hesaplandığı bir başka çalışma yapılmıştır [6].

$\mathrm{Bu}$ çalışmada Francis tipi bir türbinin belirlenen tasarım ana parametrelerine bağlı olarak boyutlandırılması yapılmış ve HAD yöntemi kullanılarak yönlendirme kanat açısının türbin gücüne ve türbin verimine etkisi incelenerek optimum yönlendirme kanat açısı belirlenmiştir. Ayrıca yönlendirme kanat açısındaki değişimlerin rotor çarkı mukavemetine etkileri de irdelenmiştir.

\section{TASARIM (DESIGN)}

$\mathrm{Bu}$ çalışmada tasarım ana parametreleri (güç, debi, düşü, devir sayısı ve özgül devir sayısı) belirlenen (Tablo 1) bir Francis tipi türbin ve çıkış borusunun tasarım boyutları (Şekil 1 ve Şekil 2), literatürde yer alan Osterien, Voith, Kuarner, Egzozarof, USA ve Leva yöntemlerine göre hesaplanmıştır. Elde edilen sonuçlara göre belirlenen tasarım ana parametrelerine (özellikle devir ve özgül devir sayılarına göre) en yakın sonuçlar veren Kuarner yöntemi sonuçları türbin ve çıkış borusu boyutlandırılmasında kullanılmıştır (Tablo 2). Şekil 3'te verilen yönlendirme kanat açısının $\beta_{\mathrm{i}, \mathrm{j}}$ 'nin $12-48^{\circ}$ aralığındaki her bir derecelik açı için HAD analizi yapılmıştır. Tasarım boyutlarına göre salyangoz, yönlendirme kanatları, çark ve çıkış borusu SolidWorks ve ANSYS programinda bulunan "Design Modeler" ile hazırlanmıştır. Akış Analizi ve sonuçları "Meshing, Fluent ve CFD post" modülleri kullanılarak gerçekleştirilmiştir.
Tablo 1. Türbin ana tasarım parametreleri (Parameters of türbine design)

\begin{tabular}{|l|l|}
\hline Net düşü & $98 \mathrm{~m}$ \\
\hline Debi & $56,15 \mathrm{~m}^{3} / \mathrm{s}$ \\
\hline Devir sayıs1 & $250 \mathrm{~min}^{-1}$ \\
\hline Özgül devir sayıs1 & $203 \mathrm{~min}^{-1}$ \\
\hline Türbin Gücü & $55,3 \mathrm{MW}$ \\
\hline
\end{tabular}

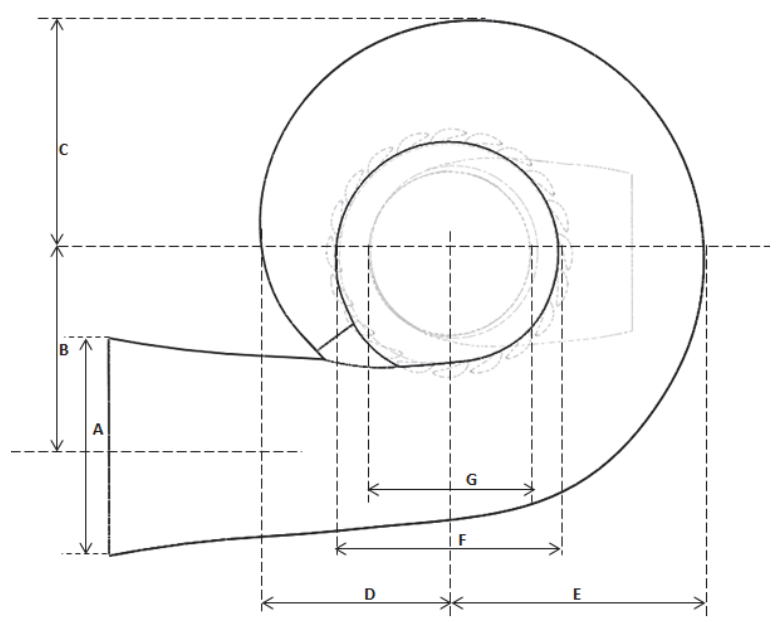

Şekil 1. Türbin tasarım boyutları (Dimensions of the turbine design)

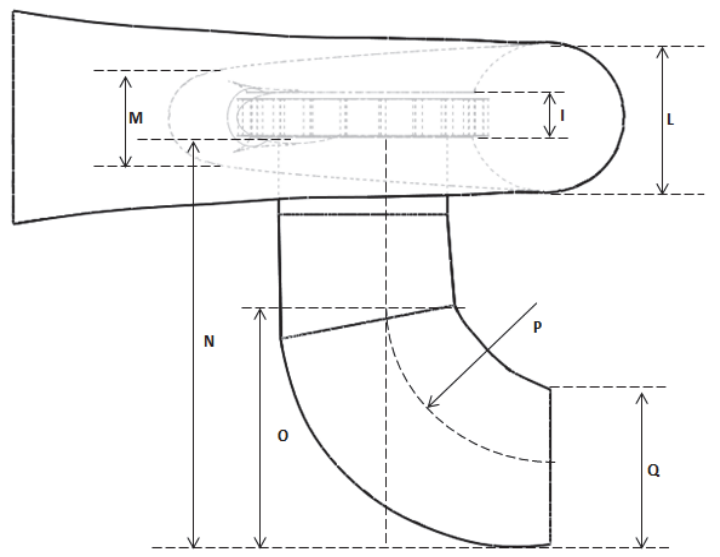

Şekil 2. Çıkış borusu tasarım boyutları (Dimensions of the exit tube design)

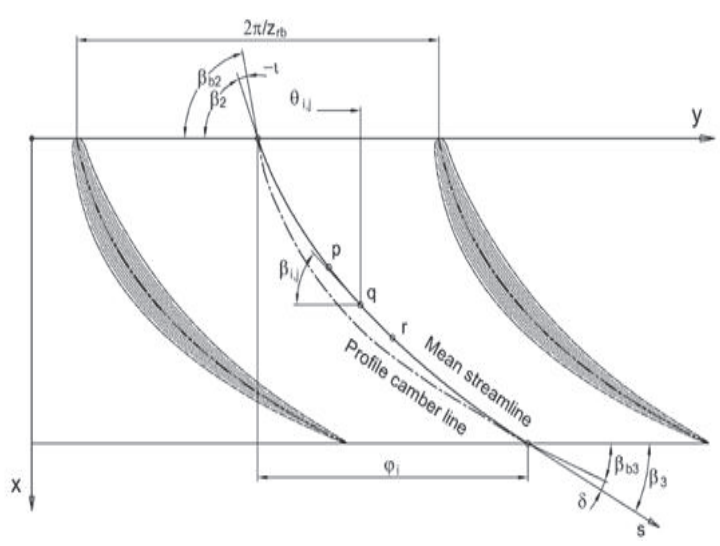

Şekil 3. Yönlendirme kanat açısı (Angle of wicket gate) 
Tablo 2. Farklı hesaplama metotlarında tasarım parametreleri (Design parameters for different calculation method)

\begin{tabular}{|c|c|c|c|c|c|c|}
\hline Parametre & Osterien & Voith & Kruner & Egyozarof & USA & Leva \\
\hline $\mathrm{D}_{3}=\left(84,5^{*} 0,753^{*}\left(\mathrm{H}_{\mathrm{d}}\right)^{\wedge} 0,5\right) /(\mathrm{n})$ & $\mathrm{D}_{3}=3,6256$ & $\mathrm{D}_{3}=3,0652$ & $\mathrm{D}_{3}=2,5379$ & $\mathrm{D}_{3}=3,1902$ & $\mathrm{D}_{3}=2,1777$ & $\mathrm{D}_{3}=2,9093$ \\
\hline $\mathrm{D}_{1}=\left(0,4+(94,5) / \mathrm{n}_{\mathrm{s}}\right)$ & $D_{1}=1,0639$ & $D_{1}=0,9613$ & $D_{1}=0,8647$ & $\mathrm{D}_{1}=0,9842$ & $\mathrm{D}_{1}=0,7988$ & $\mathrm{D}_{1}=0,9327$ \\
\hline $\mathrm{D}_{2}=\left(\mathrm{D}_{3} /\left(0,96+0,00038^{*} n_{\mathrm{s}}\right)\right)$ & $\mathrm{D}_{2}=3,5753$ & $\mathrm{D}_{2}=2,9934$ & $\mathrm{D}_{2}=2,4468$ & $\mathrm{D}_{2}=3,1232$ & $\mathrm{D}_{2}=2,0739$ & $\mathrm{D}_{2}=2,8317$ \\
\hline $\mathrm{H}_{1}=\left(0,94+0,000025 * \mathrm{n}_{\mathrm{s}}\right) * \mathrm{D}_{3}$ & $\mathrm{H}_{1}=3,4210$ & $\mathrm{H}_{1}=2,8941$ & $\mathrm{H}_{1}=2,3986$ & $\mathrm{H}_{1}=3,0117$ & $\mathrm{H}_{1}=2,0599$ & $\mathrm{H}_{1}=2,7476$ \\
\hline $\mathrm{H}_{2}=\mathrm{D}_{3} /\left(3,16-0,0013 * \mathrm{n}_{\mathrm{s}}\right)$ & $\mathrm{H}_{2}=1,2187$ & $\mathrm{H}_{2}=1,0422$ & $\mathrm{H}_{2}=0,8765$ & $\mathrm{H}_{2}=1,0815$ & $\mathrm{H}_{2}=0,7636$ & $\mathrm{H}_{2}=0,9931$ \\
\hline $\mathrm{v} 1=84,4 /\left(\mathrm{ns}^{\wedge} 0,44\right)$ & $\mathrm{v}_{1}=9,5253$ & $v_{1}=8,6460$ & $\mathrm{v}_{1}=8,1418$ & $\mathrm{v}_{1}=8,6460$ & $\mathrm{v}_{1}=8,6460$ & $\mathrm{v}_{1}=8,6460$ \\
\hline $\mathrm{A}=(1,2-(19,56 / \mathrm{ns})) * \mathrm{D}_{3}$ & $\mathrm{~A}=3,8525$ & $\mathrm{~A}=3,3221$ & $\mathrm{~A}=2,8014$ & $\mathrm{~A}=3,4425$ & $\mathrm{~A}=2,4335$ & $A=3,1703$ \\
\hline $\mathrm{B}=(1,1+(54,8 / \mathrm{ns})) * \mathrm{D}_{3}$ & $\mathrm{~B}=5,3841$ & $\mathrm{~B}=4,3693$ & $\mathrm{~B}=3,4757$ & $\mathrm{~B}=4,5900$ & $\mathrm{~B}=2,8990$ & $\mathrm{~B}=4,0990$ \\
\hline $\mathrm{C}=(1,32+(49,25 / \mathrm{ns})) * \mathrm{D}_{3}$ & $\mathrm{C}=6,0403$ & $\mathrm{C}=4,9426$ & $\mathrm{C}=3,9648$ & $\mathrm{C}=5,1824$ & $\mathrm{C}=3,3271$ & $\mathrm{C}=4,6480$ \\
\hline $\mathrm{D}=(1,50+(48,8 / \mathrm{ns})) * \mathrm{D}_{3}$ & $D=6,6815$ & $\mathrm{D}=5,4861$ & $\mathrm{D}=4,4160$ & $\mathrm{D}=5,7477$ & $\mathrm{D}=3,7150$ & $D=5,1643$ \\
\hline $\mathrm{E}=(0,98+(63,6 / \mathrm{ns})) * \mathrm{D}_{3}$ & $E=5,1731$ & $E=4,1617$ & $E=3,2810$ & $E=4,3807$ & $E=2,7186$ & $E=3,8942$ \\
\hline $\mathrm{F}=(1,00+(131,4 / \mathrm{ns})) * \mathrm{D}_{3}$ & $\mathrm{~F}=6,9726$ & $\mathrm{~F}=5,4573$ & $\mathrm{~F}=4,1780$ & $\mathrm{~F}=5,7816$ & $F=3,3852$ & $\mathrm{~F}=5,0643$ \\
\hline $\mathrm{G}=(0,89+(96,5 / \mathrm{ns})) * \mathrm{D}_{3}$ & $\mathrm{G}=5,6848$ & $\mathrm{G}=4,4848$ & $\mathrm{G}=3,4632$ & $\mathrm{G}=4,7424$ & $\mathrm{G}=2,8249$ & $\mathrm{G}=4,1719$ \\
\hline $\mathrm{H}=(0,79+(81,75 / \mathrm{ns})) * \mathrm{D}_{3}$ & $\mathrm{H}=4,9466$ & $\mathrm{H}=3,9097$ & $\mathrm{H}=3,0253$ & $\mathrm{H}=4,1325$ & $\mathrm{H}=2,4716$ & $\mathrm{H}=3,6391$ \\
\hline $\mathrm{I}=(0,1+(0,00065 * \mathrm{~ns})) * \mathrm{D}_{3}$ & $\mathrm{I}=0,6980$ & $\mathrm{I}=0,6420$ & $\mathrm{I}=0,5892$ & $\mathrm{I}=0,6545$ & $\mathrm{I}=0,5532$ & $\mathrm{I}=0,6264$ \\
\hline $\mathrm{L}=(0,88+(0,00049 * n s)) * \mathrm{D}_{3}$ & $\mathrm{~L}=3,4434$ & $\mathrm{~L}=2,95102$ & $\mathrm{~L}=2,4863$ & $\mathrm{~L}=3,0603$ & $\mathrm{~L}=2,1693$ & $\mathrm{~L}=2,8130$ \\
\hline $\mathrm{M}=\left(0,60+\left(0,000015^{*} \mathrm{~ns}\right)\right)^{*} \mathrm{D}_{3}$ & $\mathrm{M}=2,1831$ & $\mathrm{M}=1,8468$ & $\mathrm{M}=1,5305$ & $\mathrm{M}=1,9219$ & $\mathrm{M}=1,3144$ & $\mathrm{M}=1,7533$ \\
\hline $\mathrm{N}=(1,54+(203,5 / \mathrm{ns})) * \mathrm{D}_{3}$ & $\mathrm{~N}=10,7670$ & $\mathrm{~N}=8,4251$ & $\mathrm{~N}=6,4483$ & $\mathrm{~N}=8,9262$ & $\mathrm{~N}=5,2237$ & $\mathrm{~N}=7,8178$ \\
\hline $\mathrm{O}=(0,83+(140,7 / \mathrm{ns})) * \mathrm{D}_{3}$ & $\mathrm{O}=6,5931$ & $\mathrm{O}=5,1055$ & $\mathrm{O}=3,8626$ & $\mathrm{O}=5,4226$ & $\mathrm{O}=3,1004$ & $\mathrm{O}=4,7222$ \\
\hline $\mathrm{P}=(1,37-(0,00056 * \mathrm{~ns})) * \mathrm{D}_{3}$ & $\mathrm{P}=4,6781$ & $\mathrm{P}=3,9103$ & $\mathrm{P}=3,1880$ & $\mathrm{P}=4,0816$ & $\mathrm{P}=2,6944$ & $\mathrm{P}=3,6967$ \\
\hline $\mathrm{Q}=(0,58+(22,6 / \mathrm{ns})) * \mathrm{D}_{3}$ & $\mathrm{Q}=2,6785$ & $\mathrm{Q}=2,1892$ & $\mathrm{Q}=1,7541$ & $\mathrm{Q}=2,2960$ & $\mathrm{Q}=1,4707$ & $\mathrm{Q}=2,058$ \\
\hline $\mathrm{R}=(1,60-(0,13 / \mathrm{ns})) * \mathrm{D}_{3}$ & $\mathrm{R}=5,7977$ & $\mathrm{R}=4,9019$ & $\mathrm{R}=4,0591$ & $\mathrm{R}=5,1018$ & $\mathrm{R}=3,4831$ & $\mathrm{R}=4,6527$ \\
\hline $\mathrm{S}=\left((\mathrm{ns}) /((0,25 * \mathrm{~ns})-9,28)^{*} \mathrm{D}_{3}\right)$ & $\mathrm{S}=19,6188$ & $\mathrm{~S}=15,7282$ & $\mathrm{~S}=12,4188$ & $\mathrm{~S}=16,5611$ & $\mathrm{~S}=10,3286$ & $\mathrm{~S}=14,7167$ \\
\hline $\mathrm{T}=(1,50+(0,00019 / \mathrm{ns})) * \mathrm{D}_{3}$ & $\mathrm{~T}=5,4385$ & $\mathrm{~T}=4,5977$ & $\mathrm{~T}=3,8069$ & $\mathrm{~T}=4,7853$ & $T=3,2665$ & $\mathrm{~T}=4,3639$ \\
\hline $\mathrm{U}=(0,51-(0,0007 * n s)) * \mathrm{D}_{3}$ & $\mathrm{U}=1,4878$ & $\mathrm{U}=1,2020$ & $\mathrm{U}=0,9331$ & $\mathrm{U}=1,2658$ & $\mathrm{U}=0,7494$ & $\mathrm{U}=1,1225$ \\
\hline $\mathrm{V}=(1,10+(53,7 / \mathrm{ns})) * \mathrm{D}_{3}$ & $\mathrm{~V}=5,3560$ & $\mathrm{~V}=4,3493$ & $\mathrm{~V}=3,4620$ & $\mathrm{~V}=4,5683$ & $\mathrm{~V}=2,8889$ & $\mathrm{~V}=4,0809$ \\
\hline $\mathrm{Z}=(2,63+(33,8 / \mathrm{ns})) * \mathrm{D}_{3}$ & $Z=10,3964$ & $Z=8,6767$ & $Z=7,0967$ & $Z=9,0569$ & $Z=6,0379$ & $Z=8,2057$ \\
\hline $\mathrm{n}_{\mathrm{s}}$ & $\begin{array}{l}\mathrm{n}_{\mathrm{s}}= \\
3500 / \mathrm{H}_{\mathrm{d}} \wedge 0,7 \\
\mathrm{n}_{\mathrm{s}}=142\end{array}$ & $\begin{array}{l}\mathrm{n}_{\mathrm{s}}=4140 / \mathrm{H}_{\mathrm{d}} \wedge 0,7 \\
\mathrm{n}_{\mathrm{s}}=168\end{array}$ & $\begin{array}{l}\mathrm{n}_{\mathrm{s}}=5000 / \mathrm{H}_{\mathrm{d}} \wedge 0,7 \\
\mathrm{n}_{\mathrm{s}}=203\end{array}$ & $\begin{array}{l}\mathrm{n}_{\mathrm{s}}=5000 / \mathrm{H}_{\mathrm{d}} \wedge \\
0,75 \\
\mathrm{n}_{\mathrm{s}}=161 \\
\end{array}$ & $\begin{array}{l}\mathrm{n}_{\mathrm{s}}=2334 / \mathrm{H}_{\mathrm{d}} \wedge 0,5 \\
\mathrm{n}_{\mathrm{s}}=236\end{array}$ & $\begin{array}{l}\mathrm{n}_{\mathrm{s}}=3470 / \mathrm{H}_{\mathrm{d}}^{\wedge} \\
0,65 \\
\mathrm{n}_{\mathrm{s}}=177\end{array}$ \\
\hline $\mathrm{n}$ & $\begin{array}{l}\mathrm{n}=\mathrm{n}_{\mathrm{s}}^{*}\left(\left(\mathrm{H}_{\mathrm{d}} \wedge 1,25\right.\right. \\
\left.) /\left(\mathrm{P}^{\wedge} 0,5\right)\right) \\
\mathrm{n}=172\end{array}$ & $\begin{array}{l}\mathrm{n}=\mathrm{n}_{\mathrm{s}} *\left(\left(\mathrm{H}_{\mathrm{d}} \wedge 1,25\right.\right. \\
\left.) /\left(\mathrm{P}^{\wedge} 0,5\right)\right) \\
\mathrm{n}=204\end{array}$ & $\begin{array}{l}\mathrm{n}=\mathrm{n}_{\mathrm{s}}{ }^{*}\left(\left(\mathrm{H}_{\mathrm{d}}{ }^{\wedge} 1,25\right) /(\right. \\
\left.\left.\mathrm{P}^{\wedge} 0,5\right)\right) \\
\mathrm{n}=247\end{array}$ & $\begin{array}{l}\mathrm{n}=\mathrm{n}_{\mathrm{s}}^{*}\left(\left(\mathrm{H}_{\mathrm{d}} \wedge 1,25\right.\right. \\
\left.) /\left(\mathrm{P}^{\wedge} 0,5\right)\right) \\
\mathrm{n}=196\end{array}$ & $\begin{array}{l}\mathrm{n}=\mathrm{n}_{\mathrm{s}} *\left(\left(\mathrm{H}_{\mathrm{d}} \wedge 1,25\right.\right. \\
\left.) /\left(\mathrm{P}^{\wedge} 0,5\right)\right) \\
\mathrm{n}=288\end{array}$ & $\begin{array}{l}\mathrm{n}=\mathrm{n}_{\mathrm{s}}{ }^{*}\left(\left(\mathrm{H}_{\mathrm{d}}{ }^{\circ} 1,\right.\right. \\
\left.25) /\left(\mathrm{P}^{\wedge} 0,5\right)\right) \\
\mathrm{n}=215\end{array}$ \\
\hline
\end{tabular}

\subsection{Geometrik Veri ve Malzeme Özellikleri (Geometrical Data and Material Properties)}

Türbin tasarımı ANSYS programında mechanical modülüne aktarılmıștır. Mechanical modülünde Francis tipi türbini oluşturan şaft, çark, ayar kanadı, sabit kanat, spiral borusu modellenerek malzemeleri tanımlanmıştır. Spiral boru (St52), sabit ve ayar kanatlarının(13Cr4Ni), çark $(13 \mathrm{Cr} 1 \mathrm{Ni}, 13 \mathrm{Cr} 4 \mathrm{Ni}$, $16 \mathrm{Cr} 5 \mathrm{Ni}, 18 \mathrm{Cr} 8 \mathrm{Ni}$ ) ve çıkış borusunun (S355-St52) üretildikleri; karbon alaşımlı çelik (carbon steel), HSMA (High Strength Micro Alloy) ve "Heat treatment steel" gibi malzemelerin teknik özellikleri programda tanımlanmıştır.

\subsection{Düğümleme İşlemleri (Mesh Process)}

Kurulan geometrik model üzerinde sayısal çözümlemede en doğru sonuca ulaşmak için sayısal ağ modülü, üç boyutlu olarak kurulmuştur. Düğümleme modülünde üç boyutlu olarak Tetragonal tipi düğümler kullanılmıştır (Şekil 4). Sayısal çözümde yakınsama açısından önemli olan düğümlerin kalitesine bakıldığında Skewness değerinin 0'a yaklaştıkça kalitesinin yükseldiği 1'e yaklaştıkça kötüleştiği bilinmektedir [8]. Bu çalışmada hazırlanan model üzerinde kurulan düğümlerin "Skewness" değerleri incelendiğinde \%90’a yakın bölümün düğüm kalitesi 0,5 değerinin altındadır. Yapılan düğümlemede 742.977 nodes ve 502.935 element bulunmaktadır (Şekil 5).

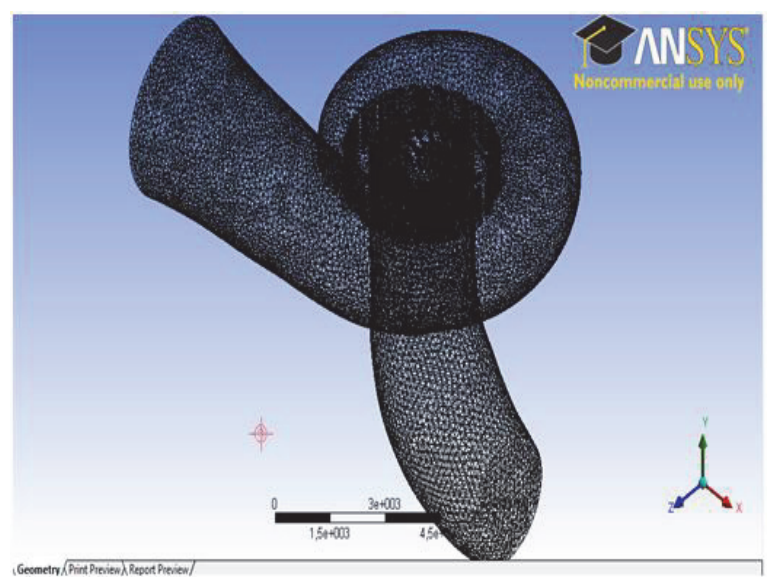

Şekil 4. Düğümleme Modülü (Meshing Module)

\subsection{Yükleme Şartları (Loading condition)}

Normal çalışma şartları altında bir Francis türbin çarkında, temelde merkezi kuvvetler ve su basıncından oluşan iki statik yük oluşmaktadır. Francis türbinde normal çalışma şartlarında merkezi kuvvetinden kaynaklanan etki, suyun basincindan oluşan etkiye göre çok daha düşüktür bu yüzden 
merkezi kuvvetten oluşan etkiler göz önüne alınmamaktadır [5,12,14]. Türbin çark kanatları üzerindeki su basıncının etkisi HAD analizinden elde edilen statik yükler aracılığıyla modellenmiştir.

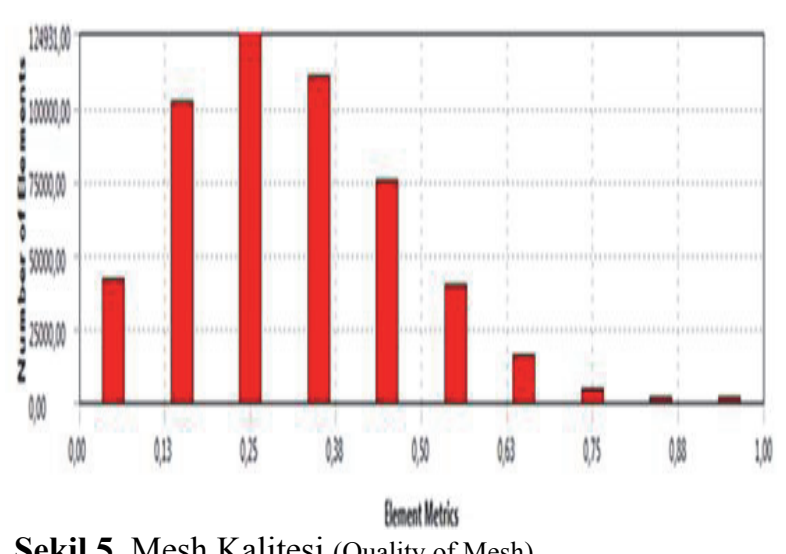

Şekil 5. Mesh Kalitesi (Quality of Mesh)

\subsection{Basınç Aktarımı (Import Pressure)}

Basınç kuvvetinin etkisiyle rotora bağlanan mil yükü devreye konularak, dönme hareketini sağlayan çarka ait "Von-Mises Equivalent Stress" değerleri incelenmiştir. Huber tarafından ortaya konan Von Misses Teorisi olarak bilinen bu teoriye göre şekil değiştirme enerjisinin belli bir sınırı aşması ile cisimde hasarın başlayacağı bunun da Von-Mises eşdeğer gerilmesi ile tarif edileceği ve bu ifadenin enerji esasına dayanan bir hipotez kurulurken kullanılması gerektiği bildirilmiştir. Daha çok enerjinin cismin geometrisini değiştirmeye sarf edilen kısmı, yani biçim değiştirme enerjisi (Von-Mises) esas alınmıştır. Birim hacim için genel halde çarpılma enerjisi;

$$
\mathrm{U}_{\mathrm{g}}=\frac{1}{12 \mathrm{G}}\left(\begin{array}{l}
\left(\sigma_{\mathrm{x}}-\sigma_{\mathrm{y}}\right)^{2}+\left(\sigma_{\mathrm{y}}-\sigma_{\mathrm{z}}\right)^{2}+ \\
\left(\sigma_{\mathrm{z}}-\sigma_{\mathrm{x}}\right)^{2}+ \\
6\left(\tau_{\mathrm{xy}}{ }^{2}+\tau_{\mathrm{xz}}{ }^{2}+\tau_{\mathrm{yz}}{ }^{2}\right)
\end{array}\right)
$$

şeklinde verilir. Asal gerilmeler cinsinden bu ifade;

$$
U_{g}=\frac{1}{12 G}\left(\begin{array}{l}
\left(\sigma_{1}-\sigma_{2}\right)^{2}+ \\
\left(\sigma_{2}-\sigma_{3}\right)^{2}+ \\
\left(\sigma_{3}-\sigma_{1}\right)^{2}
\end{array}\right)
$$

$\mathrm{Bu}$ kritere göre bir malzemenin akması çarpılma enerjisi tek eksenli haldeki çarpılma enerjisine ulaştığı zaman olur. Tek eksenli halde:

$$
\begin{aligned}
& \mathrm{U}_{\mathrm{g}}=\frac{1}{6 \mathrm{G}} \sigma_{\mathrm{y}}{ }^{2}=\frac{1}{12 \mathrm{G}}\left(\begin{array}{l}
\left(\sigma_{1}-\sigma_{2}\right)^{2}+ \\
\left(\sigma_{2}-\sigma_{3}\right)^{2}+ \\
\left(\sigma_{3}-\sigma_{1}\right)^{2}
\end{array}\right) \\
& \Rightarrow \sigma_{\mathrm{y}}{ }^{2}=\frac{1}{2}\left(\begin{array}{l}
\left(\sigma_{1}-\sigma_{2}\right)^{2}+ \\
\left(\sigma_{2}-\sigma_{3}\right)^{2}+ \\
\left(\sigma_{3}-\sigma_{1}\right)^{2}
\end{array}\right)
\end{aligned}
$$

şeklinde tanımlanır. Bu bir nevi hasar kriteridir. Bu çalışmada çarka çarpan akışkan kuvveti üç boyutlu olarak gösterilmiştir. Tek yönlü uygulanacak bir basınç kuvvetine göre dayanım sonuçlarının daha doğru çıkması sağlanmıştır.

\section{METOT (METHOD)}

HAD programları ile türbin salyangozu ve kanatlar etrafındaki akım çizgilerinin belirlenmesi ve burada oluşan teğetsel hız bileşenlerinin türbin çarkında oluşturduğu etkiyi gözlemlemede oldukça kullanışlıdır. Bununla birlikte kanat açılarındaki değişim ile birlikte türbin çarkında oluşan kuvvet ve moment değerlerindeki değişimlerin elde edilmesinde de çok iyi sonuçlar vermektedir. Akış simülasyonlarında belirlenen geometrik modele ilişkin olarak sonlu hacimler metotları ile çözümlemeler yapılmaktadır. Yapılan çözümlemeler sonucunda türbin çarkına gelen hız ve kuvvet bileşenlerinin oluşturduğu etki yapısal analiz modülünde incelenmiştir. Yapısal analiz modülünde, akışkan tarafindan oluşturulan basınç kuvvetleri ve suyun hareketli çarkta oluşturduğu etkiler incelenmiştir. Sonlu elemanlar yöntemi kullanılarak gerçekleştirilen bu çalışmada, iki aşamalı çözüm sistemi kullanılmıştır. Birinci aşama ile HAD programı kullanılarak türbin kanat açılarının değişimleri ile türbin verimlerindeki değişme araştırılmıştır. İkinci aşamada ise kanat açılarının etkisiyle oluşan kuvvet vektörlerinin (türbin çarkının her noktasında üç boyutlu olarak etkimesi sonucunda) türbin çark malzemesinde meydana getirdiği dayanım ve gerilme etkileri incelenmiştir.

Belirlenen tasarım boyutları doğrultusunda türbin çizimleri Solidworks programında yapılmış ve binary x_t formatında ANSYS Design Modeler çizim programına aktarılarak salyangoz, çark ve çıkış borusu şeklinde üç temel bölüme ayrılmıştır. ANSYS programı Meshing modülünde, akış simülasyonuna hazır hale getirebilmek için düğümlenmiştir ve sınır şartları tanımlanmıştır. Farklı yönlendirme kanat açıları için hazırlanan her model için bu işlemler tekrar edilmiştir. Fluent programında yapılan çözümlemeler için elde edilen yakınsama grafikleri Şekil 6'da verilmiştir. Elde edilen yakınsamalar 200 iterasyondan sonra sabit kalmıştır. 


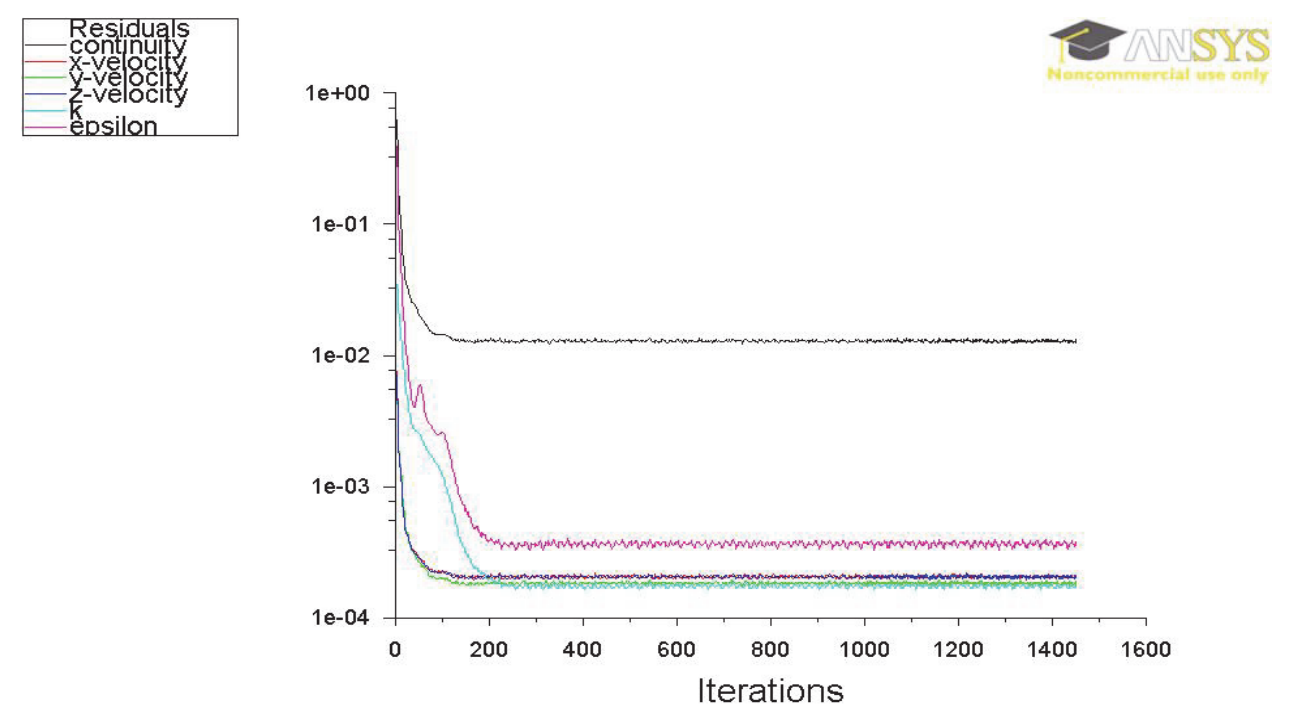

Şekil 6. Yakınsama grafiği (Converged residual)

Dönen çarka ait akış ve kontrol hacmi oluşturmuş, $250 \mathrm{~d} / \mathrm{d}$ değeri için $26.16 \mathrm{~s}^{-1}$ açısal hız değeri "y" giriş bölgesi sınır şartında giriş basıncı (pressure inlet) olarak kartezyen koordinatlarda $\mathrm{x}=1$ yönünde 13 bar'lık basınç değeri kullanılmış ve giriş bölgesi akış uzunluğu ve türbülans viskozite (turbulent viscosity) değeri \%10 olarak belirlenmiştir.

Sistem üç temel bölüme ayrılarak modellenmiştir. Basınç tabanlı çözüm sistemi kullanılarak; salyangoz, dönen çark ve çıkış borusu olarak tanımlanan sistemde $20^{\circ} \mathrm{C}$ sıcaklıkta su kullanılmıştır. Dönen sistemlerde silindirik koordinat sistemi kullanılarak analizler yapılmaktadır. Bu sistemler dönen referans eksenindeki sınırları bulundukları eksene göre açısal hız veya devir sayısı olarak ifade ederek kullanılırlar. Çıkış bölgesi sınır şartında çıkış basıncı (pressure outlet) olarak belirlenen modelde komşu yüzeylerden gelen basınç ve hız değerleri kullanılmıştır. Salyangoz içerisindeki akışkan yönlendirme kanatları vasıtasıyla rotor çarkı üzerine yönlendirilir. Buradaki amaç çark üzerine gelen akışkanın bütün enerjisini mile aktarmasının sağlanmasıdır. Çark üzerine gelen akışkanın vektörel hız dağılımı Şekil 7'deki gibidir.

Hidrolik makinalarda akışı incelemek için süreklilik denklemi, momentum denklemi ve genel enerji denklemleri kullanılır. Akışkan ve çark arasındaki enerji transferini ifade edebilmek önemlidir. Burada daimi şartlarla sınırlandırılan akış üniform kabul edilerek; m ( $\rho Q$ ) kütleli bir akışkanın çarka teğet yöndeki momentumu $\rho Q V_{s z}$ olacaktır.

Çarka giren akışkan için açısal momentum ise (yani momentumun momenti) $\rho Q V_{\mathrm{n}} r_{2}$ olacaktır. Benzer ifade çarkı terkeden akışkan içinde yazılabilir.
Böylece akışkanın açısal momentumun artma oranı $\rho Q\left(r_{2} V_{r 2}-\eta_{1} \nabla_{2}\right)$ olacaktır. Bu ifade akışkanın çark üzerine uyguladığı moment değerine eşittir.

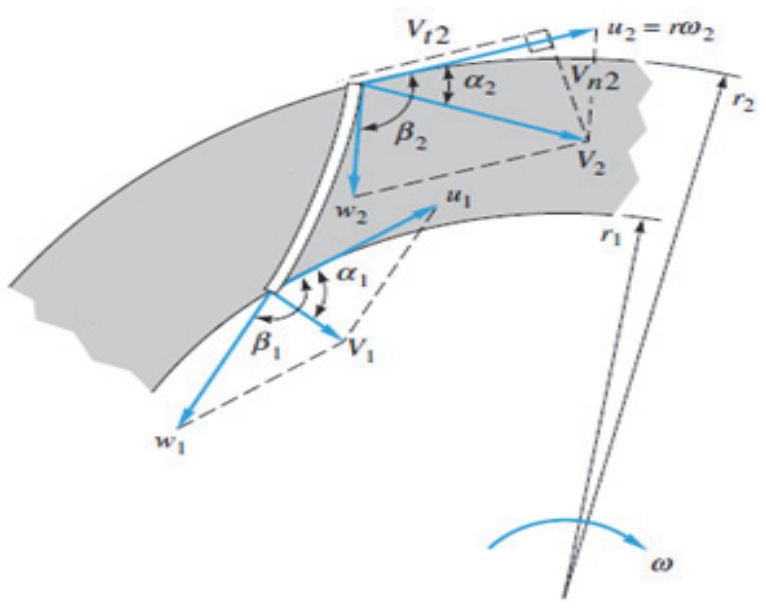

Şekil 7. Giriş çıkış hız üçgeni (Input-output speed triangle)

$T=\rho 2\left(n_{2} V_{t 2}-n_{1} V_{t 1}\right)$

$\mathrm{Bu}$ ifade Euler denklemi olarak bilinir. Türbin çarkında meydana gelen hidrolik güç ise $\mathrm{N}=\mathrm{T} \omega$ olacaktır.

$N=\omega T=\rho \omega Q\left(r_{2} V_{2}-r_{1} V_{1}\right)=\rho \omega Q\left(r_{2} V_{2} \cos \alpha_{2}-\right.$ $\left.n_{1} V_{1} \cos _{1}\right)$

Türbin için hidrolik verim ifadesi ise, bir türbinde akışkanın birim kütlesi için var olan enerjisi (gH)’nın ne kadarının türbine aktarıldığını gösteren

$\eta=\left(\eta_{2} V_{2} \cos \alpha_{2}-\eta_{1} V_{1} \cos \alpha_{1}\right) / g h$

ifade ile verilir. 


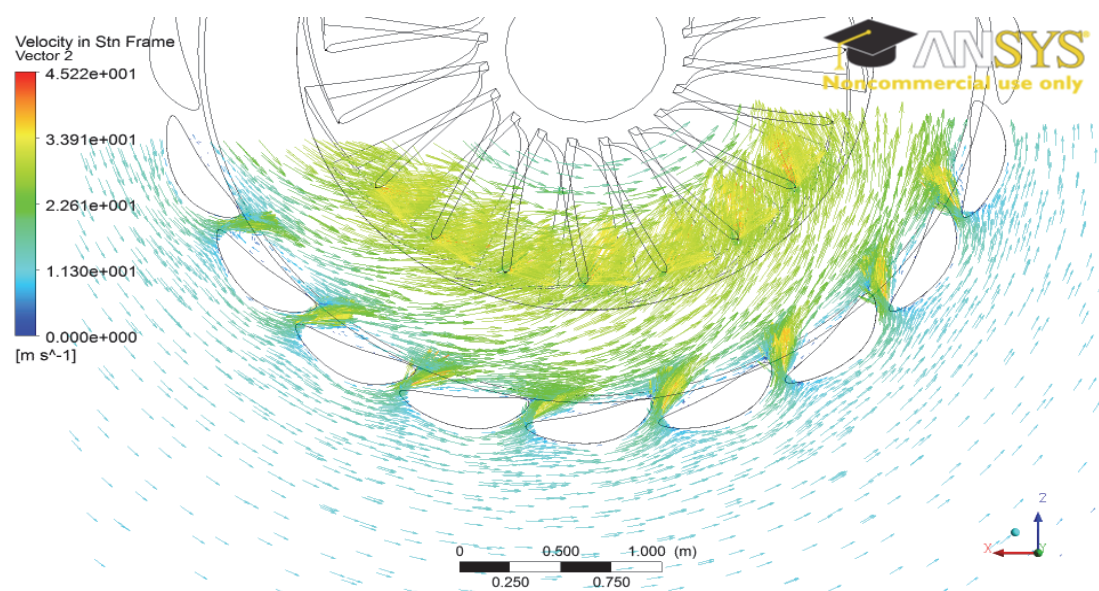

Şekil 8. $12^{\circ}$ yönlendirme kanat açılı hız dağılımları (Distributions of velocity vectors present on the wicket gate when the angle of wicket gate is $12^{\circ}$.)

\section{BULGULAR VE TARTIŞMA (RESULTS AND DISCUSSION)}

\subsection{Akış Analiz Sonuçları (Results of Fluid Flow)}

Her bir yönlendirme kanat açısı için basınç, hız, sürtünme etkileri, moment ve akım çizgileri gibi akış parametreleri incelenmiştir. Yönlendirme kanat açısının değişiminin hız vektörlerinin çark kanatlarına giriș vektörlerini etkilediği ve böylece girdap akımlarının oluşup oluşmadığı araştırılmıştır (Şekil 8).

Bununla birlikte salyangoz içinde eşit mesafelerde yerleştirilen ve akışkanın teğetsel hız bileşenini en verimli şekilde işe dönüştürmeyi sağlayan yönlendirme kanatlarının açılarında değişiklik yapılarak elde edilen moment, verim ve güç faktörleri incelenmiştir.

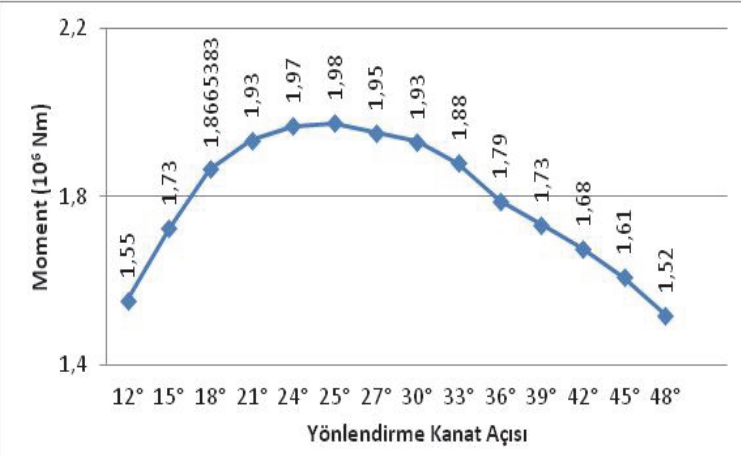

Şekil 9. Yönlendirme kanat açısına göre Moment değerleri (Torque values of the turbine for different angles of wicket gate)

Yönlendirme kanat açılarının türbin çarkında meydana getirdiği momentin değişimleri Şekil 9'da verilmiştir. Elde edilen verilere göre maksimum moment değeri $25^{\circ}$ yönlendirme kanat açısında elde edilmiștir. Türbin çarkında elde edilen moment değerlerinin $25^{\circ}$ ye kadar artma eğiliminde $25^{\circ}$ 'nin üstünde azalma eğiliminde olduğu gözlenmektedir. Moment değerleri ile birlikte türbinin 26,16 rad/s $\left(250 \mathrm{~min}^{-1}\right)$ olarak bilinen devir sayısı için türbin milinden elde edilebilecek gücün yönlendirme kanat

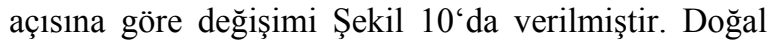
olarak momentteki değişim türbin gücündeki değişime benzer bir şekilde elde edilmiștir. Maksimum türbin gücü $25^{\circ}$ yönlendirme kanat açısında 51,68 MW olarak elde edilmiştir. Türbinin hidrolik ve çark veriminin yönlendirme kanat açısına göre değişimleri ise Şekil 11'de verilmiştir. Maksimum hidrolik ve çark verimi ise $25^{\circ}$ yönlendirme kanat açısında sırasıyla 0,95 ve 0,81 olarak elde edilmiştir.

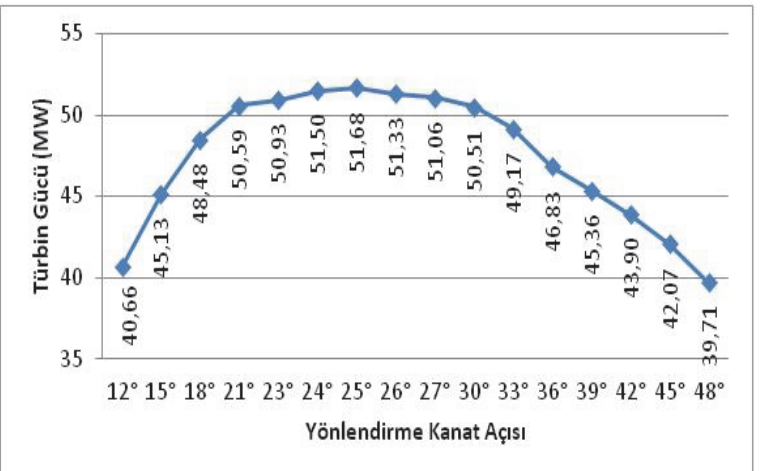

Şekil 10. Yönlendirme kanat açısına göre türbin gücü değerleri (Power of the turbine for different angles of wicket gate)

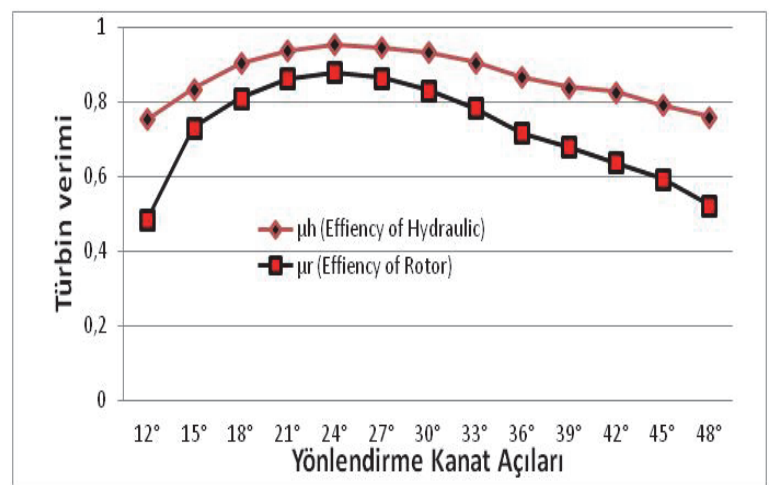

Şekil 11. Yönlendirme kanat açısının değişimine göre çark verimliliğinin değișimi (Variation of the efficiencies of the turbine with angle of the wicket gate) 


\subsection{Mukavemet Analiz Sonuçları (Results of Stress Analysis)}

"Fluent" programında her bir model için elde edilen sonuç dosyaları "Mechanical" programına alınarak yükleme şartları oluşturulmuştur. Yükleme şartlarında, türbin rotoruna gelen basınç kuvveleri her bir kanat üzerine aktarılmıştır. Ayrıca rotora bağlı türbin milinin birleştiği noktadan destek tanımlanarak, basınç kuvvetlerinden kaynaklanan mukavemet etkisinin çözümlenmesi sağlanmıştır. Çalışmada türbin çarkına gelen basınç kuvvetlerinin etkisi üç boyutlu olarak analiz edilmiştir. Türbinin içindeki karmaşık akım yüzünden, dönel ya da sabit parçalar yapısal olarak bozulabilirler. Burada, basınç yüklemeleri ve hareketli parçalarda yüksek hızda dönüş yüzünden oluşan yüklemeler göz önünde bulundurulmuştur. Basınç yüklemeleri farklı yönlendirme kanat açıları için HAD çözümlemelerinden elde edilmiştir. Çark kanatları gibi türbin parçalarındaki karma kuvvetlerin etkilerini anlayabilmek için, bu parçalardaki gerilim dağılımları parametrik (düşü, debi, moment) çalışma koşullarında hesaplanmıştır. Von-mises gerilimler 3 boyutlu çizimlerde gösterilmiş ve tasarıma uygun olabilecek malzemeler Von-mises gerilme koşullarına göre belirlenmiştir (Şekil 12). Türbin veriminin maksimum olduğu yönlendirme kanat açısındaki mukavemetler diğer açılara oranla daha azdır. Türbin dayanım incelemelerinde gerilme değerlerinin birbirine yakın çıkma sebebi, geometrik ölçülerin sabit kalması ve kullanılan debi değerinin değişiklik göstermemesidir. Rotor kanat yüzeylerinde oluşan dayanım değerleri, yönlendirme kanatlarından geçen akışkan basıncı ve teğetsel hız bileşenine bağlı olarak değişim göstermektedir. Rotor kanatlarında en büyük gerilme değerleri, rotor miline bağlanan (göbek) kısımlarında ortaya çıkmıştır. 45 ve $48^{\circ}$ yönlendirme kanat açılarında rotor çarkında meydana gelen maksimum ve minimum gerilmeler çarkın yönlendirme kanat açısı yönünde gerçekleşirken diğer açılarda ise rotor mili yönünde gerçekleşmiştir (Şekil 13). Rotor mili yönündeki maksimum gerilmeler, çark1 terkederken akışkanın üzerindeki basınç yükünü çark üzerine bırakması sonucudur. Salyangoz içerisindeki basınç değişimi yönlendirme kanat açısı $24^{\circ}$ için Şekil 14'te verilmiştir. Salyongoz içerisindeki basınç enerjisi rotor çarkında rotor miline aktarıldığ 1 için rotordan çıkışta ve çıkış borusunda düşmektedir. Dolayısıyla akışkanın rotor kanatlarına çarpmadan önceki toplam basınç enerjisini rotora vererek çıkış borusunu terkettiğini göstermektedir. Maksimum verim şartlarına ulaşılan yönlendirme kanat açılarında (24$25-27^{\circ}$ ) düşük rotor kanatlarındaki mukavemet artışları küçük artışlar gösterse de malzeme hasar mukavemeti bakımından emniyet sınırının çok çok altında kalmıştır. Şekil 15'te ise çark kanatlarında oluşan toplam deformasyon miktarı olarak $\mathrm{mm}$ cinsinden yer değiştirme mesafesi verilmiştir. Çark kanatlarında oluşan eşdeğer gerilmelerin, yönlendirme kanat açısı ve aktarım basıncına göre grafik olarak değişimleri Şekil 16'da verilmiştir.

Maksimum eşdeğer gerilmelerin olduğu yönlendirme kanat açısı $48^{\circ}$, akışkandan alınan basınç kuvvet (import pressure) değerinin maksimum olduğu kanat açısı ise $30^{\circ}$ 'dir. Türbinin maksimum verim şartlarında çalıştırılması durumunda $25^{\circ}$ yönlendirme kanat açısı tercih edildiğinde eşdeğer gerilme $5 \mathrm{MPa}$ ve alınan basınç ise $1,38 \mathrm{MPa}$ değerlerine ulaşmaktadır. Bu da çark malzemesi için seçilen $\mathrm{St}$ 1050 için emniyet gerilmesinin altındadır. $\mathrm{Bu}$ da malzeme mukavemeti bakımından yönlendirme kanat açısının optimum çalışma aralığında çalışabilirliğini göstermektedir.

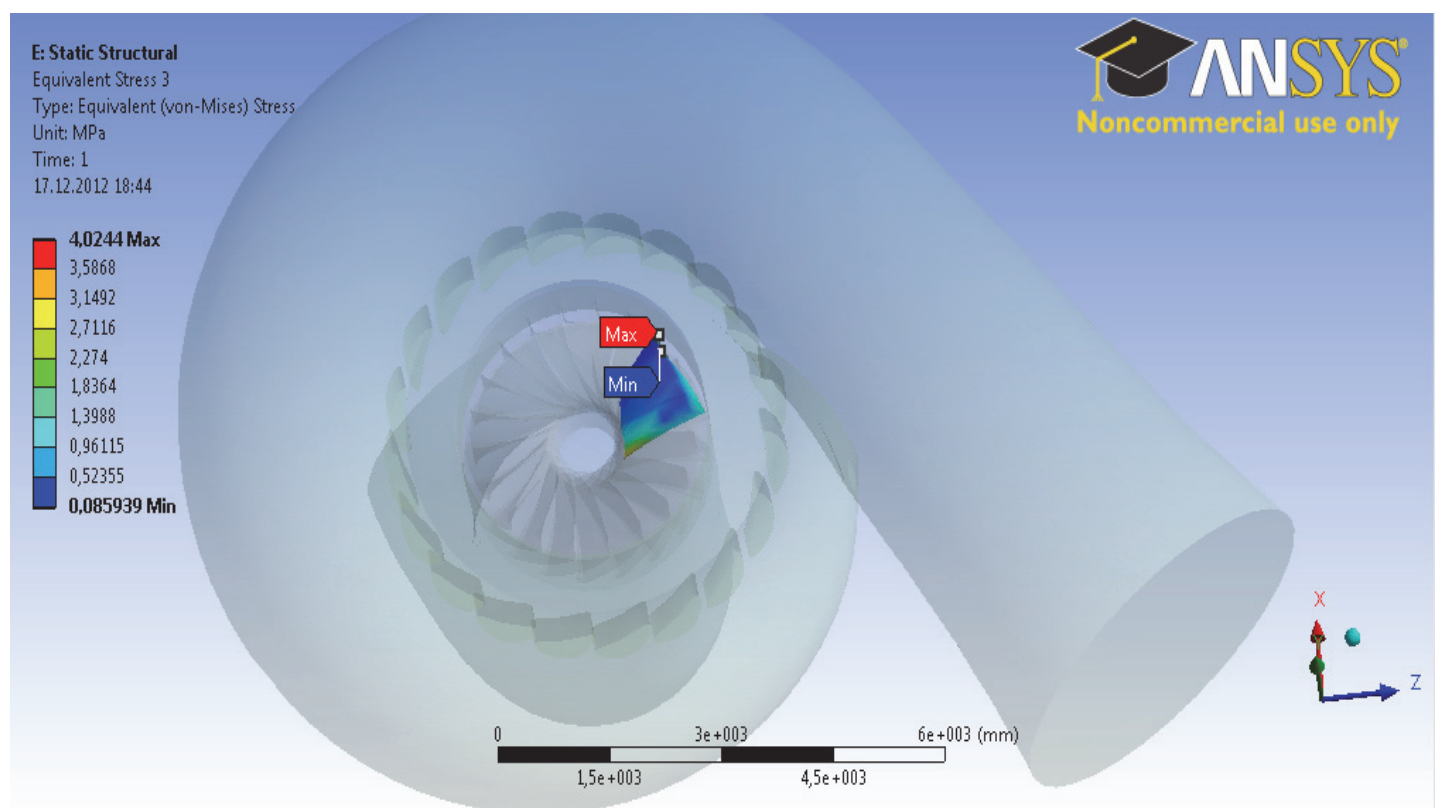

Şekil 12. Türbin çark kanadında meydana gelen Von Mises eşdeğer gerilme değerleri (Von Mises equivalent stress values occurring runner blade) 

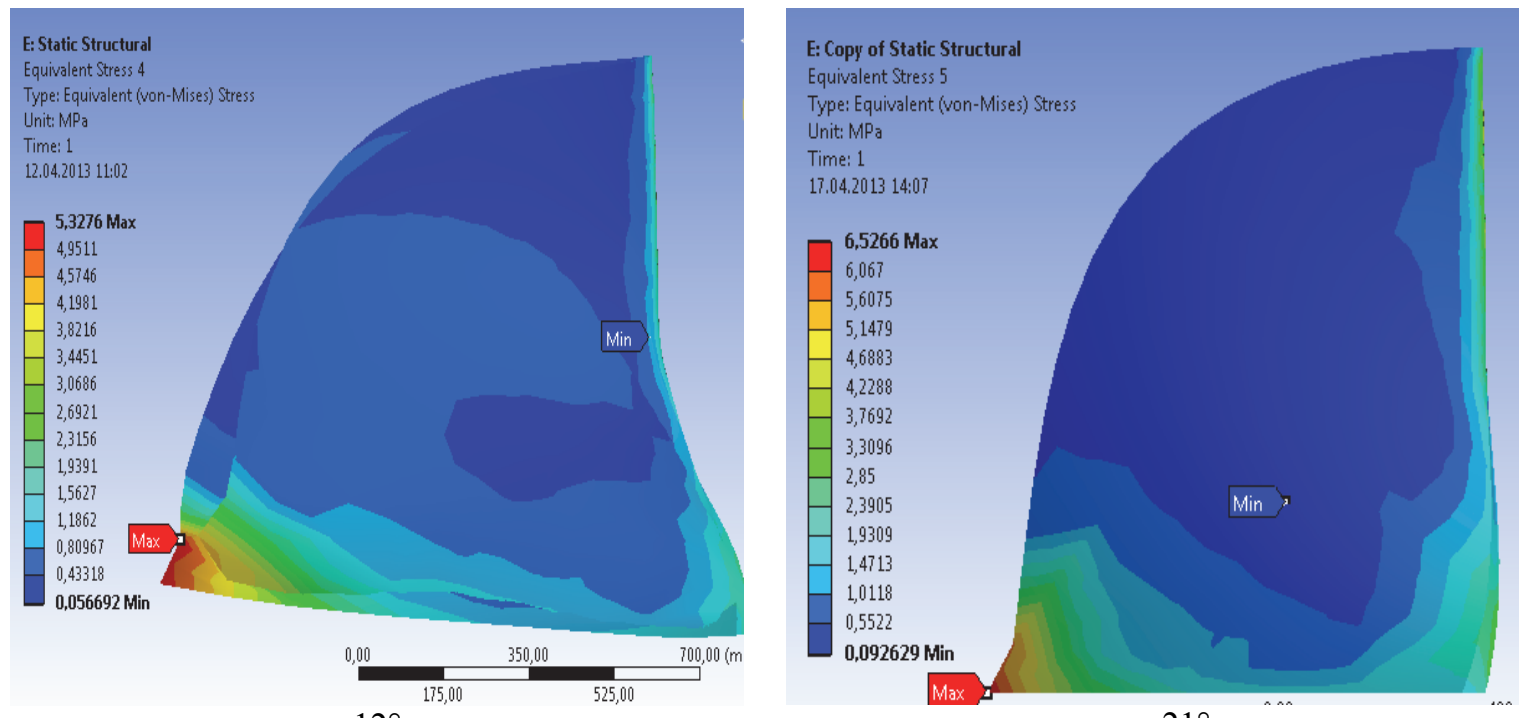

$12^{\circ}$
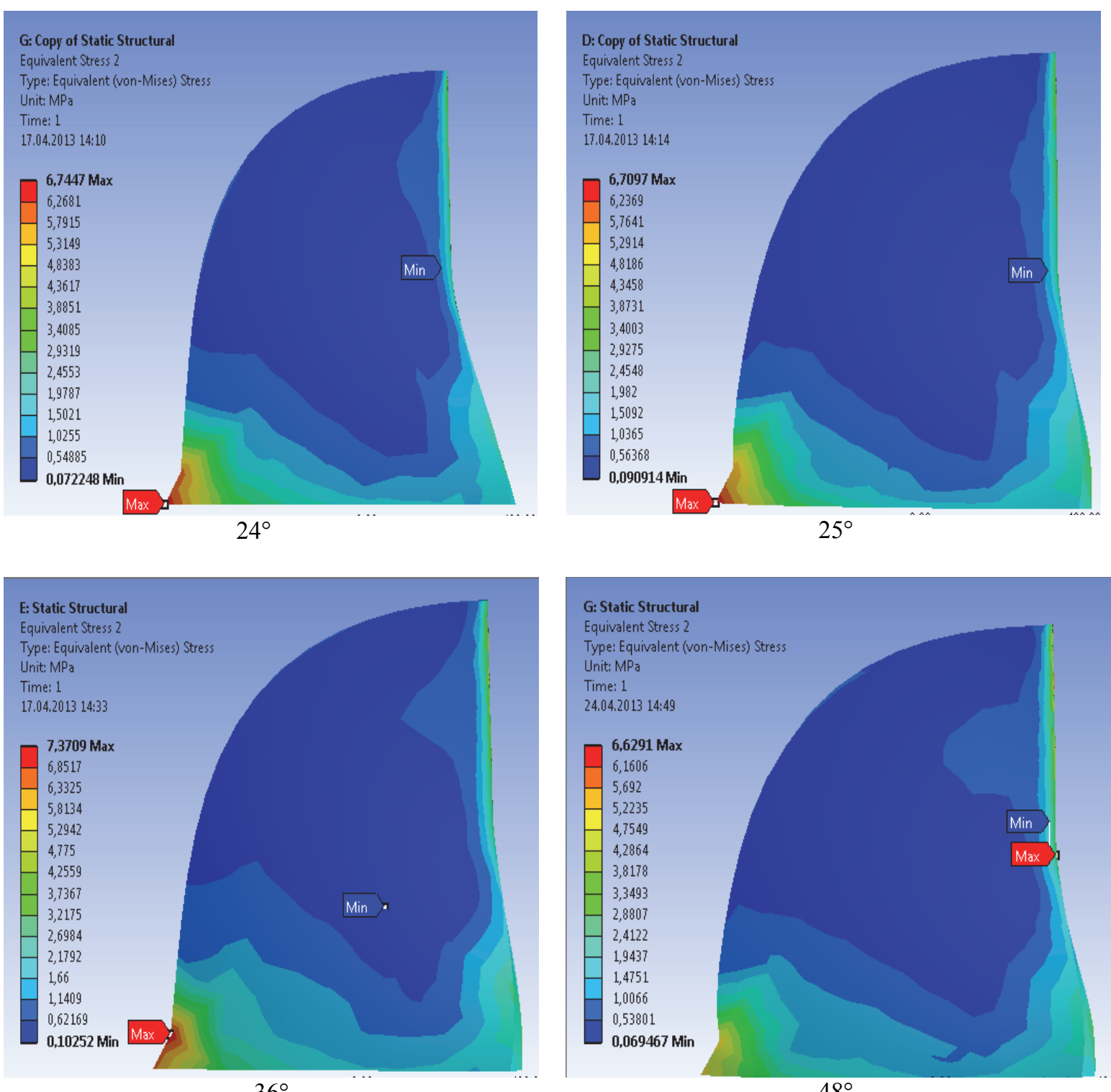

Şekil 13. Türbin çark kanadında meydana gelen maksimum ve minumum gerilmeler (maximum and minimum stresses occurring in the runner blade) 


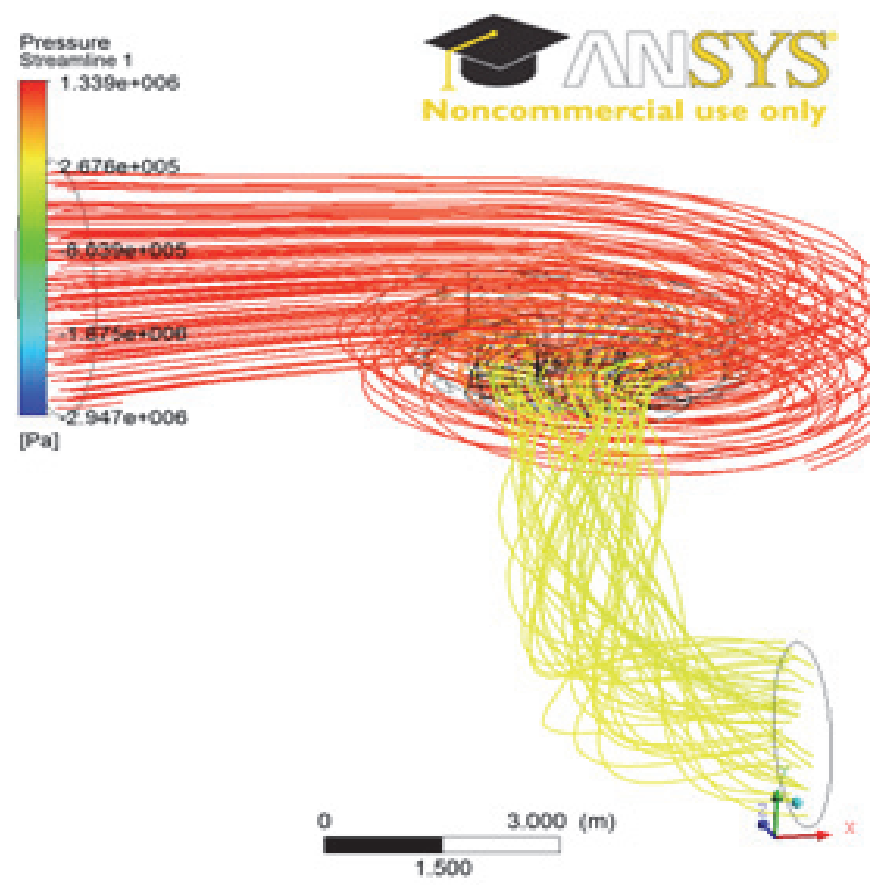

Şekil 14. Salyangoz içerisindeki basınç dağılımları (24 yönlendirme açısı için) (The pressure in the distributions snails $\left(\right.$ for $\left.24^{\circ}\right)$ )

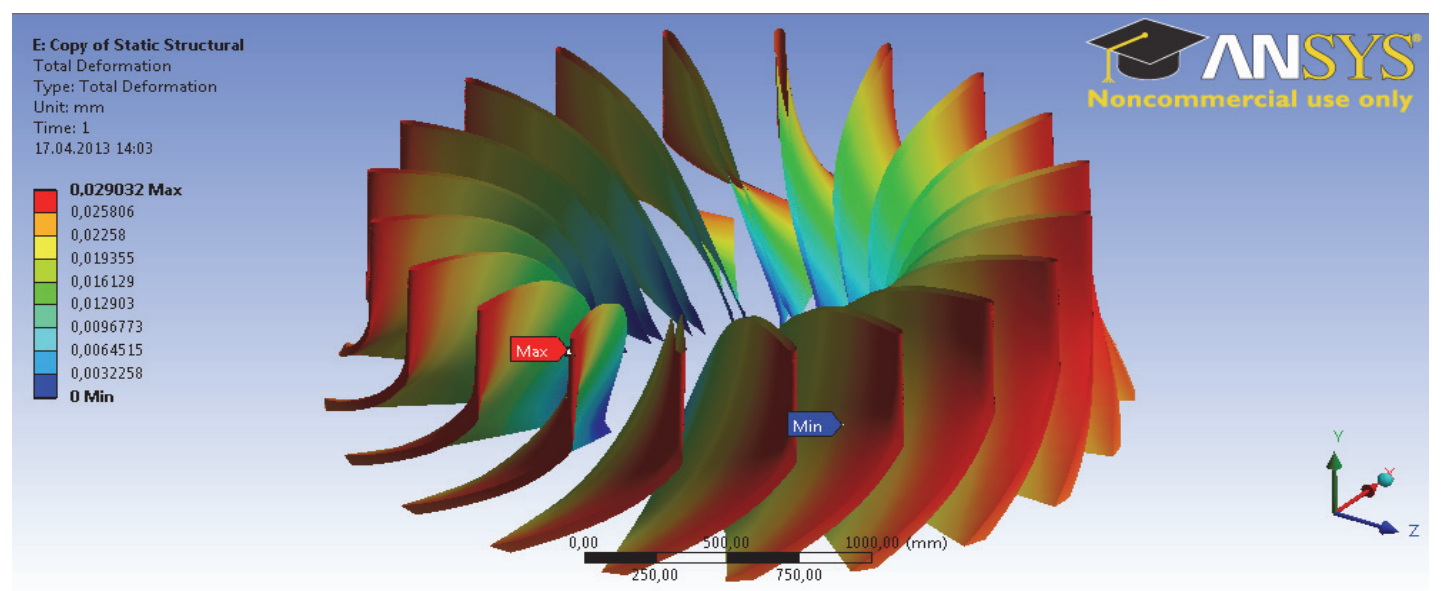

Şekil 15. $21^{\circ}$ kanat açısına göre çark yüzeylerinde meydana gelen toplam deformasyon (mm) $\left(21^{\circ}\right.$ wicket gate on the surface of the runner from the total deformation (mm))

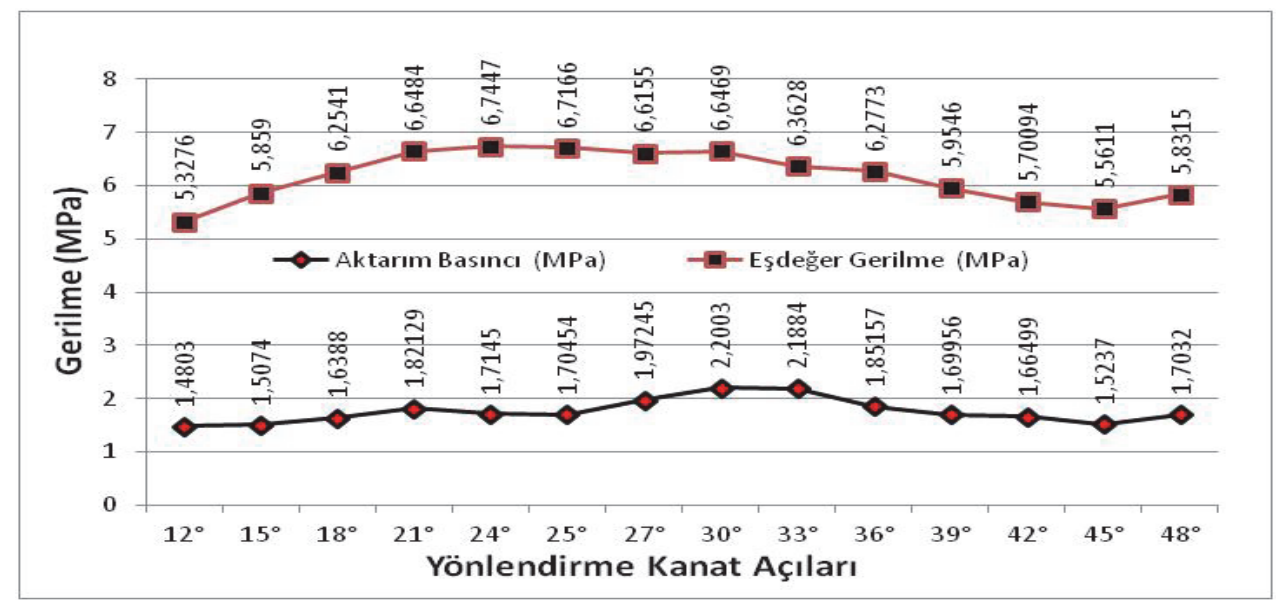

Şekil 16. Yönlendirme kanat açılarına göre çark kanatlarında oluşan eşdeğer gerilmeler (Equivallent stresses on the runner blade for different angles of wicket gate) 


\section{SONUÇLAR (CONCLUSIONS)}

Türbin veriminde yönlendirme kanat açısına bağlı değişim \%14 civarındadır. Bununla birlikte farklı kanat açılarında meydana gelen akış rejimindeki değişimler nedeniyle farklı parametrelerin (teğetsel hız bileşeni, basınç, hız ve kuvvet) türbin çarkında oluşturduğu etkiler optimum yönlendirme açısının tespitini zorunlu kılmaktadır.

Çalışma ile akış analizi sonucu maksimum çark verimini veren yönlendirme kanat açılarında kanatlar üzerine gelen basınç yüklerinin kanat mukavemeti üzerindeki etkileri de gösterilerek yönlendirme kanat açılarının türbin çark mukavemetine etkileri de sayısal olarak gösterilmiştir.

\section{KAYNAKLAR (REFERENCES)}

1. Jain, S., Saini, R.P., Kumar, A., "CFD approach for prediction of efficiency of Francis türbine" IGHEM-2010, AHEC IIT Roorkee, India, Oct. 21-23, 2010.

2. Saaed, R.A., Galybin, A.N., Popov, V., "Modelling of flow-induced stresses in a Francis turbine runner", Advances in Engineering Software, Cilt 41,1245-1255, 2010.

3. Yıldız, M., Çelebioğlu, K. "Francis Tipi Bir Türbinin Parametrik Modellenmesi”, Nuclear\&Renewable Energy Resources Conference With International Participation, Ankara - Türkiye, 402-407, 28-29 Eylül 2009.

4. Okyay, G., Çelebioğlu, K., Aydın, İ., Ger, A.M., "Francis Tipi Su Türbinlerinin Hesaplamalı Akışkanlar Dinamiği Yöntemleri İle Tasarlanması", Nuclear\&Renewable Energy Resources Conference With International Participation, Ankara-Türkiye. 388-394, 28-29 Eylül 2009.

5. Chen, W., Çelebioğlu, K., "Francis tipi su türbinlerinin sonlu elemalar yöntemi ile yapısal analizi”, Nuclear\&Renewable Energy Resources Conference With International Participation, Ankara-Türkiye, 378-383, 28-29 Eylül 2009.
6. Nilsson, H., Davidson, L.A, "Numerical Comparison of Four Operating Conditions in a Kaplan Water Turbine", Focusing on Tip Clearance Flow Published in the proceedings of the 20th IAHR Symposium, Charlotte, North Carolina-USA, 6-9 Ağustos 2000.

7. ANSYS, Inc.Fluent Theory Guide, Southpointe 275 Technology Drive Canonsburg USA, 2011.

8. Versteeg, H.K., Malalasekera, W., An Introduction to Computational Fluid Dynamics The Finite Volume Method, Pearson Prentice Hall Second edition-USA, 2007.

9. Negru, R.S. Muntean, L., Marsavina, R., SusanResiga, R., Pasca, N., "Computation of Stress Distribution in a Francis Turbine Runner Induced by Fluid Flow", Computational Materials Science, Cilt 64, 253-259, 2012.

10. Ivanchenko, I., Smelkov, L., Pupko, T., Timashkov, A., Vapnik, B., "Stress-strain state of Francis turbine blades", Power Technology and Engineering. New York: Springer;. Cilt 62, $755,1982$.

11. Ruofu, $X$, Zhengwei, W., Yongyao, L., "Dynamic Stresses in a Francis Turbine Runner Based on Fluid-Structure Interaction Analysis", Tsinghua Sci Technology Cilt 13, Say1 5, 587592, 2008.

12. Hirsch, C., Numerical computation of internal and external flows, JohnWiley \& Sons. Ltd.Oxford, Great Britain: 2007.

13. Hyen-Jun, C., Mohammed, A.Z., HyoungWoon, R., Pil-Su, H., Sueg-Young, O., YoungHo, L., "CFD Validation of Performance Improvement of a $500 \mathrm{~kW}$ Francis Turbine", Renewable Energy, Cilt 54, 111-123, 2013.

14. Zhengkun, F., Henri, C., Michel, S., Sebastien, M., "Optimal Blank Design Based on finite Element Method for Blades of Large Francis Turbines", Simulation Modelling Practice and Theory, Cilt 36, 11-21, 2013.

15. Başeşme, H., "Hidroelektrik Santraller ve Hidrolelektrik Santral Tesisleri" EÜAŞ, Ankara, 2003 Sf:95 